\title{
The Neo-Industrial Nature of the Convergence of Information and Cognitive Technologies
}

\author{
Natalia Ezdina* \\ Plekhanov Russian University of Economics, 117997 Moscow, Russia
}

\begin{abstract}
The development of information and cognitive technologies began with the advent of electronic computers. Today, with progress in the fields of grid computing and robotics, most of the tasks of electronic computers are able to solve without human assistance, thereby forming artificial intelligence. Robots and computers can not only perform a range of routine physical activities more efficiently and at lower cost than humans, but today they are also increasingly capable of performing activities that include cognitive abilities that were previously considered too difficult to automate, for example, the acceptance of tacit judgments, the perception of emotions. This predetermines the neo-industrial role of the convergence of information and cognitive technologies, which should form a platform for neo-industrial development. The latter is possible with the accelerated diffusion of convergent technologies in industry, in which they must replace production technologies that have reached their limit. Such a technological transition should be based not on the branch, but on the supra-branch principle of structural genesis. In its turn, to do this, it is necessary to take into account both the benefits and risks of neo-industrial modernization of industry based on convergent technologies. This is the social effect of information-and-convergent neo-industrialization.
\end{abstract}

\section{Introduction}

One of the key features of the new industrial revolution in the Industry 4.0 format is the integration of industry technologies at all levels of the economic system. Technologies of a new type - convergent ones - which represent a synthesis of innovative developments in various directions in science, necessitate the involvement of end-to-end methods of diffusion of technologies in the traditional industry structure. The synergistic effect of technological convergence of interaction between developers, manufacturers and investors is accompanied by a transformative influence on traditional hierarchical structures and chains for value creation. As a result, neo-industrialization of a new type of economy is being formed - a convergent-technological one, when, on the one hand, fundamentally new industries are created - genetic engineering and nano-biochemistry, computer science of artificial intelligence (Cognitive IT), the economy of knowledge and self-replicating technologies. On the other hand, cognitive technologies are penetrating basic industries, creating bioenergy, bio-informatics, nanorobotics and nanomaterials. Information technologies that combine the

\footnotetext{
* Corresponding author: ezdinanp@list.ru
} 
processes of investment, development, creation and promotion of modern goods on the market are the platform of convertible technological neo-industrialization.

Taking into account the supra-branch principle of functioning of convergent technologies and a wide scope of practical application, their development and distribution will take place outside the sectoral structure, which will lead to shifts in the structure of the economy and the formation of new institutional mechanisms of digitalization and neo-industrial development.

\section{Materials and Methods}

The process of convergent technological neo-industrial development of the economy, regardless of the methodology of its research, is based on the replacement of basic technologies with fundamentally new technologies, which are subsequently accompanied by the necessary additional innovations and have certain patterns of their development [1]. Since 2001, under the auspices of the US National Science Foundation, the so-called NBICinitiative [2] (nanotechnology, biotechnology, information and cognitive sciences) has been launched, which denotes a kind of convergent whole [3]. For the diffusion of Industry 4.0 technologies in manufacturing, the most important is the convergence of information and cognitive technologies, which combine the knowledge economy and informatics into artificial intelligence and machine learning systems.

The prospects for the participation of convergent information and cognitive technologies in the neo-industrialization of the economy can be represented as an S-curve. The mathematical model of the S-curve, which has interdisciplinary application, illustrates the process of changing innovative technologies in the course of their genesis, sectoral transfer and inter-sectoral diffusion [4]. The S-curve reflects the inevitability of technology obsolescence and a decrease in the return on investment in R\&D as it is further modernized. According to the theory of A.D. Little, technologies in their development go through four stages: genesis, growth, maturity and saturation [5]. The stage of genesis is characterized by a low degree of technology diffusion, the period of growth is characterized by a higher degree, but still insufficiently embodied in new goods and services. During maturity, converged technologies are highly competitive and are widely used in key industries. At the stage of saturation, all technologies lose their competitive advantages and are gradually replaced by new progressive technologies (Fig. 1).

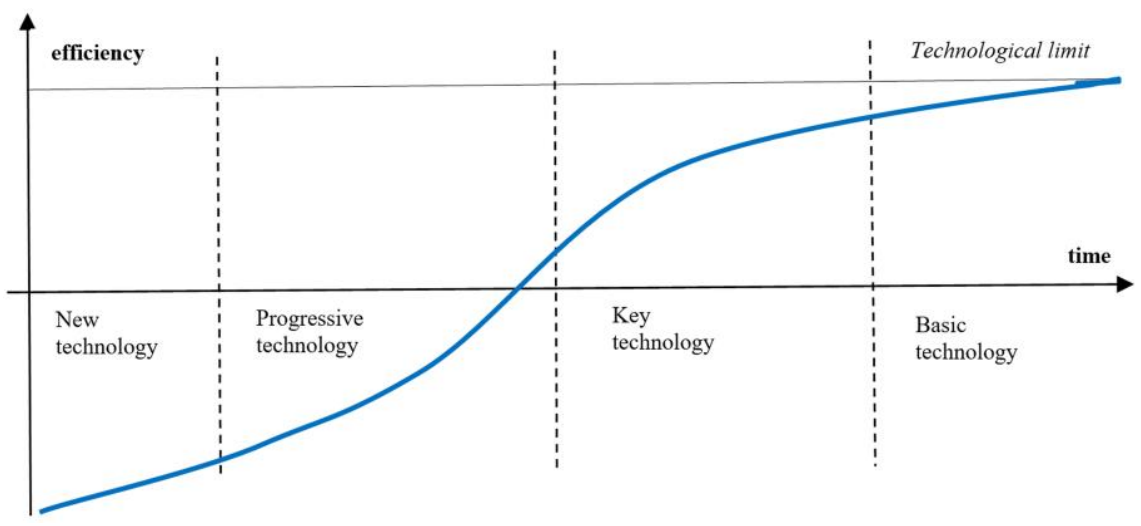

Fig. 1. Classification of technologies by stage of the life cycle (S-curve) - connection of the S-curve and A.D. Little theory of the innovation cycle 
As follows from Fig. 1, the positive impact of convergent technologies on the innovative development of industry (the technological platform of neo-industrialization) has its own technological limit [6]. It occurs at the maturity stage and characterizes its maximum possible production potential. New technologies are the result of R\&D and need further development. Progressive technologies are used in an extremely small number of developments, but they have great potential for competitiveness. Key technologies are technologies that are at the forefront of technological development, providing a strong competitive advantage. Basic technologies are traditional, very widespread, do not provide any competitive advantages, and the costs of their refinement and improvement are impractical. Another type of technology can be distinguished - the displaced one (technology that are being replaced by more advanced ones).

The industry restructuring for the standards of Industry 4.0 promises unprecedented growth in labor productivity and profits for companies that form a productive force based on artificial intelligence as a result of information and cognitive technologies convergence. However, the existing concepts of technological layers and technical and economic paradigms cannot be fully applicable in the context of today's technological transition from specific industrial information technologies to convergent ones [7]. A fundamentally new approach to the periodization of technological development consists in the recognition of the sectoral principle of the spread of technological innovations obsolete. The nature and functioning of a new type of convergent technology requires the emergence of new mechanisms for the diffusion of developments. The identification of a number of industries as "carriers", playing a leading role in the spread of the technological order, seems to contradict the new principle of structure formation within the framework of convergent technological neo-industrialization [8]. As a result of changes in genesis sources that affect the technological structure of economy, both the principles of the spread of technological innovations and the content of structural shifts are undergoing changes. The latter acquires a truly neo-industrial character, when basic industries become consumers of converged technologies and go through deep modernization.

\section{Results and Discussion}

The expansion of convergent information and cognitive technologies in the 2010s generated a significant structural shift in the sectoral distribution of GDP in technologically advanced countries. This is evidenced by the following statistics. In the early $2000 \mathrm{~s}$, the leaders in attracting investments were the processing and oil and gas companies (General Electric and Exxon, as well as the manufacturer of traditional PC software - Microsoft). By 2006, refining and petrochemical companies finally took the top three (Total ousted Microsoft from it). By the end of 2010, with stable demand and high energy prices from the world's largest corporations - leaders in terms of capitalization - three of five were employed in oil production: Shell, PetroChina, Exxon. The expansion of convergent technologies, mainly information and cognitive technologies, has led to the fact that in five years - by 2016, no oil and gas corporation entered the top five. Instead of them, the world capitalization rating today is presented by companies - leaders in information technology (Amazon, Facebook) and artificial intelligence (Apple, Alphabet, Microsoft) - Fig. 2. [9]. 


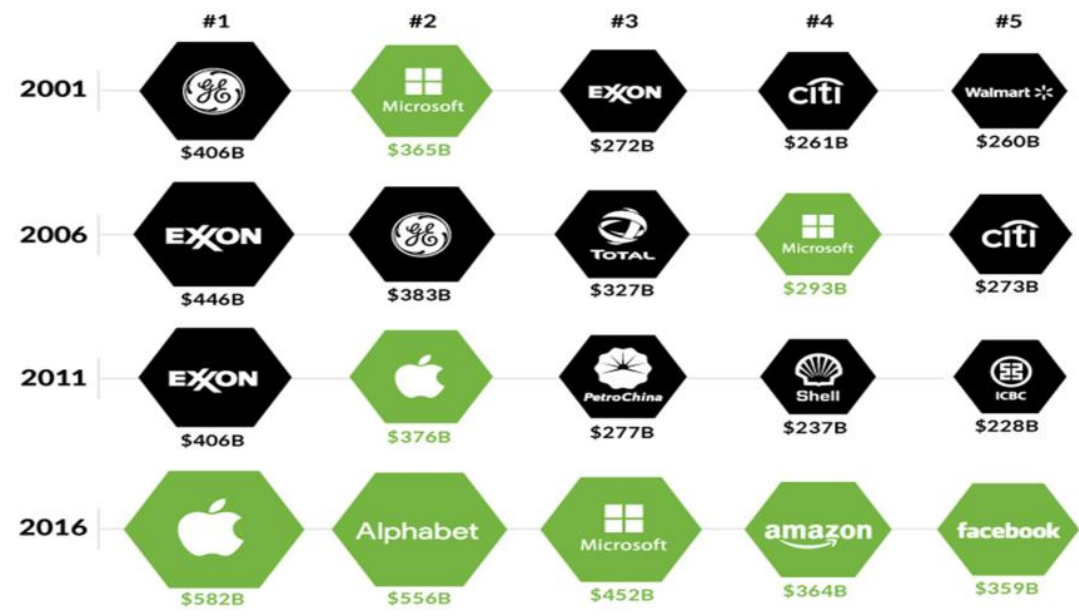

Fig. 2. Five of the largest corporations by market capitalization

The McKinsey Global Institute has identified 12 convergent technologies that are expected to make a technological platform for neo-industrialization on a global scale in the next five years - the massive replacement of means of production in basic industries with new ones with multiply higher productivity [10]. The most promising of them are information technologies that converge with cognitive and nano-material technologies: mobile Internet and Internet of things (IoT), artificial intelligence in mental labor. By 2025, the profitability from the introduction of these technologies is expected at the level of 12-23 USD trillion. Other results of the diffusion of convergent technologies are even more promising: cloud technologies, autonomous vehicles, genetic engineering, bioenergy and industrial 3D printing.

Convergent technologies, which are already forming the platform for global neoindustrialization, and the expected economic effect of their diffusion, are shown in Fig. 3 [10].

\begin{tabular}{|c|c|c|c|c|c|c|c|c|c|c|c|c|c|}
\hline \multicolumn{14}{|c|}{ Expected impact by 2025 , trillions of dollars annually } \\
\hline$N$ & Technology name & 0 & 1 & 2 & 3 & 4 & 5 & 6 & 7 & 8 & 9 & 10 & 11 \\
\hline 1 & Mobile Internet & & & & & & & & & & & & \\
\hline 2 & $\begin{array}{l}\text { Artificial } \\
\text { Intelligence }\end{array}$ & & & & & & & & & & & & \\
\hline 3 & Internet of things & & & & & & & & & & & & \\
\hline 4 & Cloud technologies & & & & & & & & & & & & \\
\hline 5 & Robotics & & & & & & & & & & & & \\
\hline 6 & $\begin{array}{l}\text { Autonomous } \\
\text { and unmanned } \\
\text { vehicles }\end{array}$ & & & & & & & & & & & & \\
\hline 7 & Genetic Engineering & & & & & & & & & & & & \\
\hline 8 & Energy storage & & & & & & & & & & & & \\
\hline 9 & 3D Printing & & & & & & & & & & & & \\
\hline 10 & Nanomaterials & & & & & & & & & & & & \\
\hline 11 & $\begin{array}{l}\text { New methods of oil } \\
\text { and gas production }\end{array}$ & & & & & & & & & & & & \\
\hline 12 & $\begin{array}{l}\text { Renewable energy } \\
\text { sources }\end{array}$ & & & & & & & & & & & & \\
\hline
\end{tabular}

Fig. 3. Top 12 convergent technologies and their possible economic effect by 2025

As the diffusion of convergent technologies develops with the formation of new industries, it is information technologies that will determine the course of the neo-industrial transformation of almost all sectors of economic and social life. This will be primarily due to an increase in the availability of the Internet, in particular, the 5G mobile Internet, the number 
of users of which will increase by 3.5 billion by 2025 [11]. As a result, millions of people will have the opportunity of distance education and employment, access to advanced healthcare technologies. Due to deep digitalization, it seems possible to reduce costs in healthcare by $10-20 \%$, in administrative activities by $60-75 \%$. Labor productivity can increase significantly: in retail trade by $6-15 \%$, in transaction management of payment systems - by $50 \%$ [12].

The essence and inter-disciplinarity of convergent technologies make it possible to determine them as technologies with a supra-branch principle of functioning, possessing a high ability for inter-branch diffusion, significant synergistic potential and having a systemic effect on nano-, micro-, meso-, macro- and mega-levels of the economic system. Through a time lag of 20-30 years, the synergistic effect from the introduction of convergent information technologies will lead to their widespread distribution in traditional industries and the formation of new industries.

In this regard, it is important to highlight those industries in which converged information and cognitive technologies, primarily artificial intelligence, the Internet of things and machine learning, have shown the most specific results, significantly increasing productivity and giving users new, undeniable competitive advantages.

For example, in the industry of transportation, freight and passenger logistics, information and cognitive breakthrough has led to the emergence of cyber systems for controlling superfast transport flows in real time, adaptive roads, unmanned vehicles, and the operation of cargo drones. In the UK, a large-scale railway transformation project has been launched since 2016, with the goals of improving safety, increasing traffic volumes, increasing customer convenience (access to all information and purchasing tickets through mobile devices), creating a flexible schedule designed to quickly respond to the needs of passengers and traffic pattern control in real time. There is the possibility of automatic regulation of train movement and the possibility of creating bi-directional tracks, which will increase the volume of traffic and make the infrastructure more productive. The sensors installed on the tracks provide trains with the necessary information and report it to the traffic control center, there is a continuous two-way data exchange.

Such technologies have already been tested in air transportation in the UK: the throughput of Heathrow Airport has increased by $61 \%$ over the past 50 years due to the introduction of digital technologies. $22 \%$ reduction in travel time and $55.7 \%$ reduction in the number of incidents on the road were achieved with the help of information and communication technologies in the highway system, which allow tracking incidents and transmitting information to drivers in a timely manner. The London Underground increased its capacity by about $40 \%$, passenger traffic by $3 \%$, reduced electricity consumption by $30 \%$ and reduced delays by 5000 hours thanks to automatic alarm systems, digital equipment, digital control centers and the ability to monitor all systems remotely. [13]

In the field of bioenergy, a large-scale sectoral structural shift is being formed, which will result in the replacement of fossil energy sources with wind, solar, tidal water, subsoil heat, and biogas. Alternative energy will improve the environmental situation, increase energy efficiency through a system of networks with intelligent control, and make energy more affordable. This is possible not only due to the development of new forms of generation, but also due to the use of artificial intelligence for dispatching. Now, the UK is the leader in the production of energy from wind; in 2017, the world's largest wind farm with 32 installations with a total area of 40 square kilometers was launched [14]. Due to the fact that the volume of energy produced by alternative sources cannot be predicted, this has led to such an economic effect as negative electricity prices. In the UK, due to the large amount of energy received and stable demand, negative energy prices were observed for 5 hours.

The key directions for the implementation of convergent information and cognitive technologies in medicine and the production of new generation of pharmaceuticals (with 
individual properties) are the personalization of medicine, the use of artificial intelligence in diagnostics and treatment, and 3D printing of donor organs. Today we can give a number of examples of the functioning of the "medicine of the future" based on artificial intelligence. For example, the IBM Watson supercomputer uses over 600,000 medical reports, 2 million pages of text from 42 medical scientific journals and clinical trial results in the field of cancer research to provide the doctor with treatment recommendations. Analysis of 1.5 million case histories and long-term therapy of oncological diseases in just a few seconds allows making faster and more informed decisions about the patient's treatment [15]. The potential for the online medicine market is huge. Thus, in China, by 2020, it can amount to about 110 billion dollars. [16] The state contributes to this: it has already financed electronic health records, the creation of information systems and reduced institutional barriers by simplifying the registration of online pharmacies and allowing remote prescriptions in remote areas.

Using Big Data as the means of information processing has a number of advantages. First, Big Data makes information transparent and usable at a much higher level. Secondly, because the data is stored digitally, it allows for more accurate and detailed information, for example, on productivity in all aspects of production, making adjustments and thereby increasing productivity. Third, Big Data provides tighter customer segmentation and hence the production of much more personalized products or services. Fourth, sophisticated analytics can dramatically improve decision-making. Finally, Big Ddata can be used to improve the development of the next generation of products and services. For example, manufacturers use data from sensors embedded in products to create innovative after-sales service offerings such as predictive maintenance (preventive measures that are taken before a failure occurs).

Cloud computing is increasing the availability of information; it is a computational model in which users buy IT products as a service. Users can access IT products at any time, regardless of location, track usage, and grow their IT capabilities as needed, without investing heavily in software or hardware. Conventional computers reaching the limits of their computational power are being replaced by quantum computers focused on solving more specialized problems that require extremely reliable computing. Computing systems of quantum type, using the laws of quantum mechanics for calculation, today are multitasking: they search for drugs that can focus on specific types of disease and assess the risk of an investment portfolio. Such systems are used to improve performance, to solve problems faster than conventional computers. In addition, information and communication channels operating on the basis of quantum technologies make it possible to transmit information absolutely confidentially.

\section{Conclusion}

The greatest synergistic effect from the diffusion of convergent technologies into the structure of economy will be achieved if there is a technological base of the digital economy at the corresponding level of development. The integration potential of information and convergent technologies can be realized in industry as much as possible only if the "receiving" technologies of material production are science-intensive. And this is the neoindustrial path of technological modernization, in which the innovative development of basic industries that have reached their technological limit is inspired by convergent technologies. Such a technological transition will make it possible to withdraw the Russian economy from the number of catching-up countries, subject to the implementation of a convergent-oriented technological policy. At the same time, a prerequisite for the penetration of convergent technologies into complex production systems is the predominance of high-tech production sectors in the economy structure. 


\section{References}

1. N. Ezdina, E3S Web Conf., 21, 04015 (2017)

2. E. Dotsenko, E3S Web Conf., 21, 04013 (2017)

3. M. C. Roco, W. S. Bainbridge, Converging technologies for improving human performance: nanotechnology, biotechnology, information technology and cognitive science (2003)

4. B. Barlow, The S-Curve of Business: The Key Levers to Sustaining Momentum for Your Brand (2014)

5. A. D. Little, The Strategic Management of Technology (1981)

6. E. Dotsenko, N. Ezdina, D. Caganova, S. Mudrova, E3S Web Conf., 174, 04039 (2020)

7. S. Zhironkin, O. Aleshina, V. Gorev, Y. Gunyakov, O. Zhironkina, E3S Web Conf., 105, 04001 (2019)

8. E. V. Slesarenko, Economics and Innovation Management, 4, 4 (2018)

9. The Largest Companies by Market Cap Over 15 Years, http://www.visualcapitalist.com/

10. McKinsey Digital. Disruptive technologies: Advances that will transform life, business, and the global economy, https://www.mckinsey.com/

11. A. L. Volkova, O. U. Korneva, Economics and Innovation Management, 2, 32 (2019)

12. UNESCO Science Report 2018 (2018)

13. V. P. Kupriyanovsky, Int. J. of Open Information Technologies, 4(10), 22 (2016)

14. Mersey feat: world's biggest wind turbines go online near Liverpool, https://www.theguardian.com/

15. Y. Chen, G. Weber, Clinical Therapeutics, 38(4), 688 (2016)

16. A. Holzinger, M. Dehmer, I. Jurisica, BMC Bioinformatics, 15(6), I1.3 (2014) 